\title{
Efficiency Enhancement of Permanent-Magnet Synchronous Motor Drives by Online Loss Minimization Approaches
}

\author{
Calogero Cavallaro, Antonino Oscar Di Tommaso, Rosario Miceli, Member, IEEE, \\ Angelo Raciti, Senior Member, IEEE, Giuseppe Ricco Galluzzo, and Marco Trapanese, Member, IEEE
}

\begin{abstract}
In this paper, a new loss minimization control algorithm for inverter-fed permanent-magnet synchronous motors (PMSMs), which allows for the reduction of the power losses of the electric drive without penalty on its dynamic performance, is analyzed, experimentally realized, and validated. In particular, after a brief recounting of two loss minimization control strategies, namely, the "search control" and the "loss-model control," both a new modified dynamic model of the PMSM (which takes into account the iron losses) and an innovative "loss-model" control strategy are presented. Experimental tests on a specific PMSM drive employing the proposed loss minimization algorithm have been performed, aiming to validate the actual implementation. The main results of these tests confirm that the dynamic performance of the drive is maintained, and in small motors enhancement up to $3.5 \%$ of the efficiency can be reached in comparison with the PMSM drive equipped with a more traditional control strategy.
\end{abstract}

Index Terms-Control systems, efficiency improvement, permanent-magnet synchronous motor (PMSM), variable-speed motor drives.

\section{NOMENCLATURE}

$i_{d}, i_{q}$

$i_{c d}, i_{c q}$

$v_{d}, v_{q}$

$L_{d}, L_{q}$

$L_{l d}, L_{l q}$

$L_{m d}$,

$L_{m q}$

$k$

$R, R_{c}$

$\lambda_{\mathrm{PM}}$

$P$

$\omega$

$\omega_{r}$

$T_{e}$

$T_{m}$
$J$
$C$
$F$
$\theta_{r}$

Rotor inertia.

Coulomb friction coefficient.

Viscous friction coefficient.

Instantaneous angular position of the rotor.

\section{INTRODUCTION} tween any wasted energy and the consequent negative decrease of the global quality of the ambient has been well demonstrated. In particular, this applies to the electrical consumption, which involves complicated industrial processes for the electric energy generation. Thus, long-term operation of electrical drives, which are noticeable load-consuming equipment like those for electric vehicle propulsion or industrial apparatus (compressors, fans, pumps, machine tools, etc.), are expected to have high energetic efficiency as one of the most important figures to reach. The whole efficiency depends on the single efficiency of the different components of the electric drives. It is worth noting that by using optimal control strategies it is possible to reduce the losses of the electric drives, without relevant decrease of the dynamic performance of the drive.

Thanks to their high performance, permanent-magnet synchronous motors (PMSMs) are widely used in industrial drive applications. The main advantages, which are highly appreciated in comparison to those of other solutions (dc and induction motors), are the high efficiency and the high power-weight ratio. PMSMs are convenient because they have a loss-free rotor, and power losses are mainly related to the stator windings and the stator stack. The ratio of the copper and iron power losses is a key issue in determining the maximum efficiency point as a function of the mechanical load that is driven by the motor shaft. In the case of constant-speed motors fed by the mains, the motor design is obtained as a tradeoff that gives the maximum efficiency point at given load conditions, according to the user requirements. Unfortunately, this suitable condition is no longer maintained as long as the motors operate at variable-torque and variable-speed conditions.

This paper deals with a control algorithm, which is able to reduce the losses (copper and iron losses) of interior PMSM drives, through the injection of the proper direct-axis current in the stator winding, in the case of variabl-speed and variable-torque applications. In particular, after a brief recounting of two loss minimization control strategies [1]-[3] (the so-called 
"search control" and "loss-model control"), both a new modified dynamic model of the PMSM that also takes into account the iron losses and an innovative optimization procedure of the "loss-model" control strategy, previously investigated by the authors [4], are presented. The control algorithm allows determining the optimal direct-axis current according to the operating speed and the load conditions. In particular, a robust algorithm, suitable for all kind of PMSMs, is used in order to obtain, in a fast and simple way, the optimal solution. The exploited approach can be applied to both machines with magnetic isotropy and anisotropy in the rotor, but the best results seem to be obtainable with the latter ones. The control algorithm is designed to improve the efficiency in steady-state condition, which is a major opportunity for energy savings.

Experimental tests on a specific PMSM drive employing the proposed loss minimization algorithm (LMA) have shown that its dynamic performance is maintained, and in small motors enhancement up to $3.5 \%$ of the efficiency can be reached in comparison to the PMSM drive equipped with a more traditional control strategy (namely, the $i_{d}=0$ ).

\section{State of The ART Of Loss Minimization TeChniQues}

Control techniques aimedat obtaining the loss minimization have been extensively investigated in the literature. However, despite the great number of papers they can strictly be summarized into three main categories [5]-[10]: papers that deal with the "loss-model control" technique, papers that apply the "search control" algorithm, and papers that use the simple state control (SSC). The "loss-model control" technique is based on the development of a mathematical model, which allows estimating the energy losses occurring during the running of the motor. Obviously, key issues in this case are the knowledge of a precise system model, an accurate identification of its parameters, and also the variation of the parameters with the temperature, current, etc. By expressing the losses as a function of the control variables of the drive, it is possible to impose an operating condition to obtain maximum efficiency [1].

The "search control" algorithm, on the contrary, is not based on a model, but rather on an adaptive routine. The approach mainly consists of changing step by step the value of a control variable, then measuring for each operating point the active power flowing into the motor. Finally, by comparing the measurement result with the previous one at fixed operating conditions, the minimum power consumption of the drive is searched. To this aim, recent work has experimentally demonstrated that the searching procedure can successfully individuate a maximum efficiency point [2]. The "search control" algorithm has the advantage that there is no need to know the model of the motor and its parameters. A drawback is that such a technique can originate system oscillation phenomena, thus, making the drive unstable. As far as this technique is adopted, a requirement of an additional stabilization network can take place [6].

\section{PMSM DYNAMIC MODEL THAT INCLUDES THE IRON LOSSES}

The basic hypotheses, which have been used in order to define the proposed dynamic model of a PMSM, are that the spatial dis-

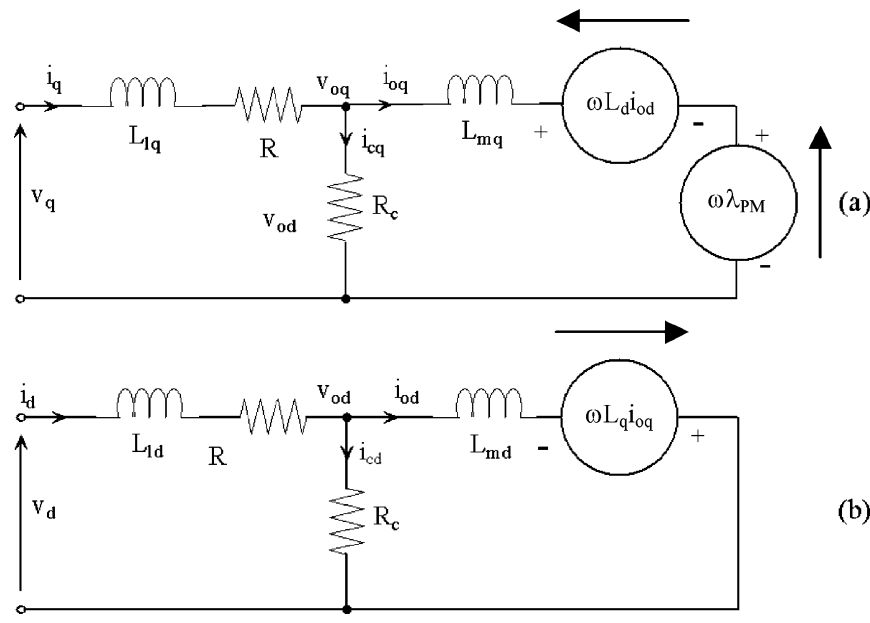

Fig. 1. Dynamic $d-q$-axes equivalent circuits of a PMSM.

tribution of the magnetic flux in the air gap is sinusoidal and the magnetic circuit is linear. Moreover, a dedicated parameter has been considered aimed at accounting for the iron losses on the stator stack. In particular, the iron losses are modeled by a resistance $R_{c}$, which is inserted in the traditional equivalent circuits of a synchronous machine so that the power loss depends on the air-gap linkage flux. Accordingly, by considering the two-axis theory of Park and introducing the change in the model as defined above to account for the iron losses, the dynamic $d$ - and $q$-axes equivalent circuits of the PMSM can be drawn, as shown in Fig. 1. With reference to Fig. 1, the state equations of the dynamic model of a PMSM, also taking into account the iron losses, are

$$
\begin{aligned}
\frac{d i_{d}}{d t} & =\frac{1}{L_{l d}}\left(v_{d}-R i_{d}-L_{m d} \frac{d i_{o d}}{d t}+L_{q} P \omega_{r} i_{o q}\right) \\
\frac{d i_{q}}{d t} & =\frac{1}{L_{l q}}\left(v_{q}-R i_{q}-L_{m q} \frac{d i_{o q}}{d t}-L_{d} P \omega_{r} i_{o d}-\lambda_{\mathrm{PM}} P \omega_{r}\right) \\
\frac{d \omega_{r}}{d t} & =\frac{1}{J}\left[T_{e}-C \operatorname{Sign}\left(\omega_{r}\right)-F \omega_{r}-T_{m}\right] \\
\frac{d \theta_{r}}{d t} & =\omega_{r}=\frac{\omega}{P}
\end{aligned}
$$

where

$$
\begin{aligned}
& i_{o d}=i_{d}-i_{c d} \text { and } i_{o q}=i_{q}-i_{c q} \\
& i_{c d}=\frac{-\omega k L_{d} i_{o q}+L_{m d} \frac{d i_{o d}}{d t}}{R_{c}}
\end{aligned}
$$

with $k=L_{q} / L_{d}$

$$
\begin{aligned}
i_{c q} & =\frac{\omega\left(\lambda_{\mathrm{PM}}+L_{d} i_{o d}\right)+L_{m q} \frac{d i_{o q}}{d t}}{R_{c}} \\
T_{e} & =\frac{3}{2} P\left[\lambda_{\mathrm{PM}} i_{o q}+\left(L_{m d}-L_{m q}\right) i_{o d} i_{o q}\right] .
\end{aligned}
$$

\section{LMA}

The power losses in a PMSM are copper and iron losses in the stator, mechanical losses, and additional losses. The last ones are related to both the copper and iron, and are neglected here for 
the sake of simplicity and, also, because their values are difficult to estimate, are normally evaluated as a percentage of the rated power. Moreover, since the technique presented in this paper causes a field weakening under every operating condition, the effect of the additional losses is reduced in comparison to other control techniques. However, a better understanding of the physical phenomena underlying the additional losses could definitely improve every minimization technique. Splitting these considered losses into two categories, namely, controllable and uncontrollable losses, can allow for a more work-oriented analysis.

The copper losses, which are mainly determined by the fundamental harmonic component of the stator current, and the iron losses, which are determined by the fundamental harmonic component of the total linkage flux, belong to the first type (in turn, these losses depend on the controllable variables of the motor). Unlike the above quantities, copper and iron losses that are caused by the higher harmonic components, along with the mechanical losses, belong to the uncontrollable ones.

By referring (1) and (2) and (5) and (6) to a steady-state condition, it is possible to find a mathematical expression of the power losses that are caused by the fundamental harmonic of the current in the windings $\left(W_{\mathrm{Cu}}\right)$. In a similar manner, the power losses that are caused by the fundamental harmonic of the total linkage flux in the iron stack $\left(W_{\mathrm{Fe}}\right)$ can be determined. In turn, the controllable electrical losses may be expressed as a function of the $i_{o d}$ and $i_{o q}$ current components and also of the electrical speed, for example, $\omega=P \omega_{r}$

$$
\begin{aligned}
& W_{\mathrm{Cu}}\left(i_{o d}, i_{o q}, \omega\right) \\
& =\frac{3}{2} R\left(i_{d}^{2}+i_{q}^{2}\right) \\
& =\frac{3}{2} R\left\{\left(i_{o d}-\frac{\omega L_{q} i_{o q}}{R_{c}}\right)^{2}+\left(i_{o q}+\frac{\omega\left(\lambda_{\mathrm{PM}}+L_{d} i_{o d}\right)}{R_{c}}\right)^{2}\right\} \\
& W_{\mathrm{Fe}}\left(i_{o d}, i_{o q}, \omega\right) \\
& =\frac{3}{2} R_{c}\left(i_{c d}^{2}+i_{c q}^{2}\right) \\
& =\frac{3}{2} \frac{\omega^{2}}{R_{c}}\left[\left(L_{q} i_{o q}\right)^{2}+\left(\lambda_{\mathrm{PM}}+L_{d} i_{o d}\right)^{2}\right]
\end{aligned}
$$

Accordingly, the total electrical losses are

$$
W_{C}\left(i_{o d}, i_{o q}, \omega\right)=W_{\mathrm{Cu}}+W_{\mathrm{Fe}}
$$

The controllable losses in steady-state condition may be obtained by combining (7) and (10). The result is a relation that expresses the power losses of the motor as function of the electromagnetic torque $T_{e}$, of the direct-axis current component $i_{o d}$, and of the angular speed $\omega_{r}$. In detail

$$
W_{C}\left(i_{o d}, T_{e}, \omega\right)=W_{\mathrm{Cu}}\left(i_{o d}, T_{e}, \omega\right)+W_{\mathrm{Fe}}\left(i_{o d}, T_{e}, \omega\right)
$$

A simple consideration can be carried out based on inspection of relation (11): at fixed values of both $T_{e}$ and $\omega$, the total controllable losses only depend on the $i_{\text {od }}$ value, and then they can be minimized by adjusting the direct-axis current. The determination of the minimum of (11) can be pursued by adopting an iterative numerical algorithm. The result of such a search is the minimum of the function (11) obtained at a particular value

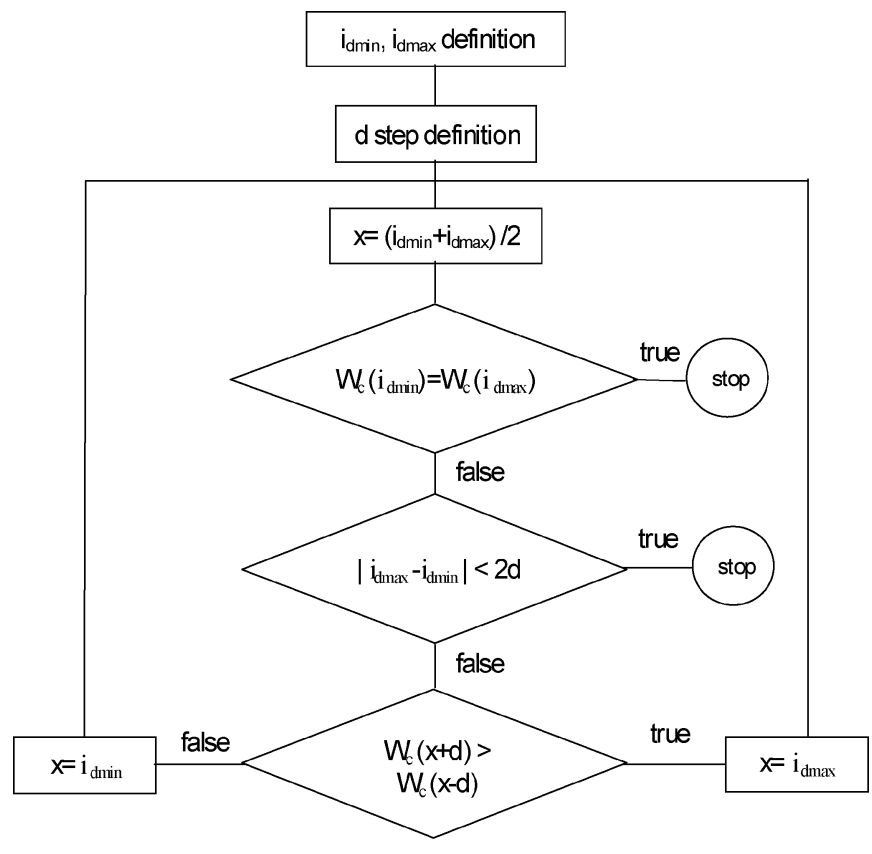

Fig. 2. Flowchart of the search algorithm. The quantities $i_{d \text { min }}$ and $i_{d \text { max }}$ are the search interval limits (two values of currents in the case of study), $d$ is the search step, $x$ the average test point of the interval $\left(i_{d \min }, i_{d \max }\right)$, and $W_{c}(x)$ is the power consumption.

of the $i_{\text {od }}$ current, under the hypothesis that both the load torque and the angular speed are unchanged.

In [1], the value of $i_{o d}$ that minimizes the electrical losses has been analytically calculated by differentiating expression (11), with respect to the $i_{o d}$ variable, and successively equating the resulting expression to zero. The following relations summarize the main results of such a procedure, being the previous solutions of (11) and a key step in understanding the advantages of the proposed implementation of the LMA.

Let

$$
A B=T_{e}^{2} C
$$

where

$$
\begin{aligned}
& A=P^{2}\left[R R_{c}^{2} i_{o d}+\omega^{2} L_{d}\left(R+R_{c}\right)\left(L_{d} i_{o d}+\lambda_{\mathrm{PM}}\right)\right] \\
& B=\left[\lambda_{\mathrm{PM}}+(1-k) L_{d} i_{o d}\right]^{3} \\
& C=\left[R R_{c}^{2}+\left(R+R_{c}\right)\left(\omega k L_{d}\right)^{2}\right](1-k) L_{d} .
\end{aligned}
$$

In the case of machines with isotropic rotor structure the parameter of saliency is $k=1$ and conditions (12)-(15) simplify. Accordingly, the optimal current $i_{o d} *$ can be easily expressed as an analytical function [1]. However, for a more general structure of the motor rotor, the problem cannot be easily solved, and a closed solution $i_{o d} *$ is not obtainable, because of the nonlinear relationship nature of $((12)-(15))$. For this reason, in [1] the value of $i_{o d} *$ which minimizes the losses has been calculated by using an approximate procedure. By the use of a polynomial expression, which is a function of $i_{o q}$, whose coefficients are also functions of the speed, the solution of the optimal $d$-axis current is calculated in real time. The speed dependence of the 


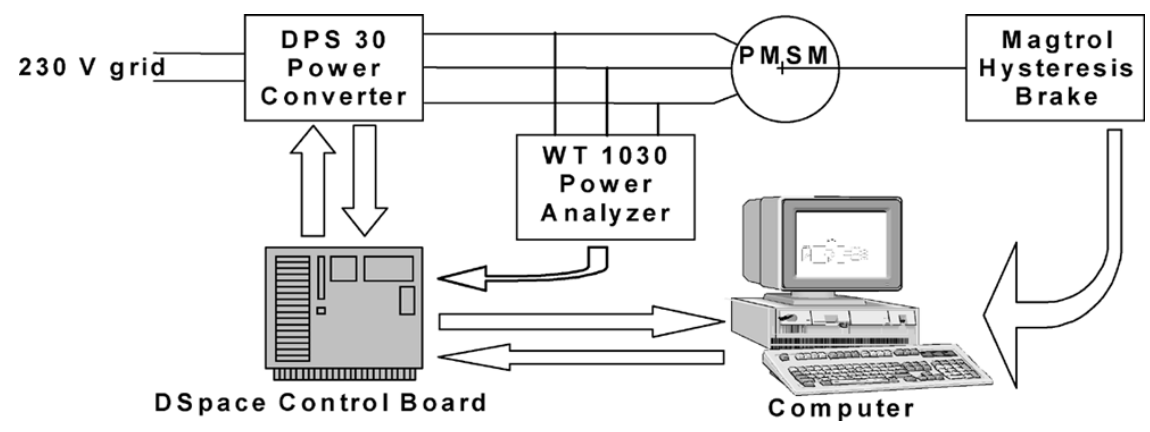

Fig. 3. Simplified block schematic of the PMSM drive test bench.

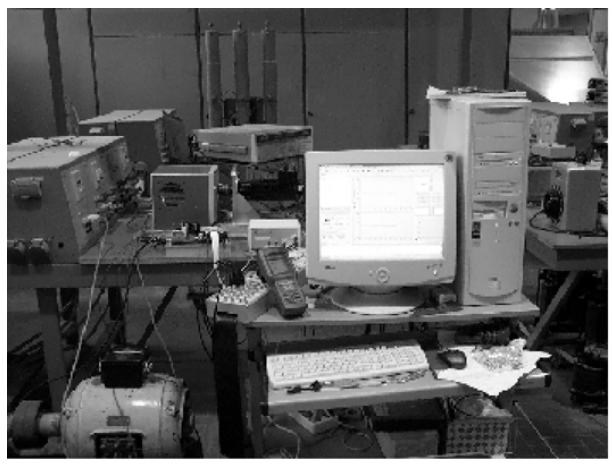

a)

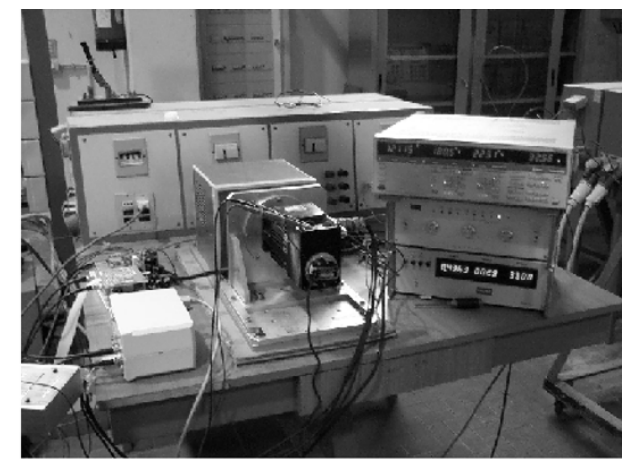

b)

Fig. 4. Details of the laboratory room. (a) Test bench. (b) Particular of the PMSM with the converter, the controlled brake, and the power analyzer.

polynomial coefficient is implemented through the use of a previously calculated lookup table. This method has the burden relative to the recalculation of a lot of coefficients, in order to update the lookup table, aiming to account for the new parameters in case the motor is changed.

Alternatively, in this paper a simple and effective methodology that may be applied to directly solve the above problem has been implemented. In particular, an interval-reduction algorithm has been chosen [10], it being a useful and robust calculation procedure for all those functions that feature in the search interval only a local minimum. The flowchart of this algorithm is depicted in Fig. 2. It can be seen how this approach is substantially a "binary search" algorithm. Validation tests of such a procedure, which has been integrated into the drive controller, have shown that it converges within about 13 iterations for an 11-A search range $\left(i_{d \min }=-10 \mathrm{~A}\right.$ and $\left.i_{d \max }=1 \mathrm{~A}\right)$ amplitude and a search step fixed at $1 \mathrm{~mA}$. Moreover, the procedure lasts in a time interval ranging from 50 to $100 \mu \mathrm{s}$. The procedure is now described in more detail. By fixing the range of the search interval $\left(i_{d \min }\right.$ and $\left.i_{d \max }\right)$ and the search step amplitude $(d)$ the midpoint $(x)$ is calculated. Now, if $W_{c}(x-d)>W_{c}(x+d)$ then $x=i_{d \max }$, otherwise $x=i_{d \text { min }}$. This calculation is iterated until $\left|i_{d \text { min }}-i_{d \max }\right|<2 d$ giving the value of $i_{d}$ which minimizes the power consumption of the electrical drive.

\section{Actual Implementation of the Proposed Procedure IN AN EXPERIMENTAL TEST BENCH}

A test bench for the validation of the LMA has been realized by implementing the proposed control system in a laboratory prototype of a PMSM electrical drive. The set rig is com- posed of a controlled load, a three-phase power analyzer having a $200-\mathrm{kHz}$ bandwidth, and the PMSM electrical drive under test. A simplified representation by a block diagram of the test bench is shown in Fig. 3. More details of the experimental setup are shown in the photographs of the electrical drive laboratory, Fig. 4(a) and (b).

In more detail, the PMSM electrical drive under test is composed of a radial flux PMSM, an insulated-gate-bipolar-transistor (IGBT)-based converter, and a dSPACE rapid prototyping system that drives the IGBT converter according to a field-oriented control strategy. In Fig. 5, a block diagram of the PMSM electrical drive is depicted. In this schematic the block named "speed controller" determines the required motor torque, according to the speed error, and the LMA calculates, within each sampling period of the speed control loop (the sampling period is $\left.T_{s}=100 \mu \mathrm{s}\right)$, the instantaneous values of $i_{d}$ and $i_{q}$, which are the components of the stator reference currents, based on relations (5), (6), and (11). According to the procedure that has been outlined above, the inputs of the LMA block are the instantaneous angular speed and the reference torque coming out of the speed controller.

The LMA, the speed, and the current loops have been fully implemented on the dSPACE board. The output signals of the PWM generator that come from the dSPACE board are then directly fed to the driving circuits of the IGBT switches.

\section{EXPERIMENTAL RESULTS}

Extensive laboratory tests have been carried out. The aim was both the validation of the correctness of the loss estimation model, which is expressed by relation (11), and the effective- 


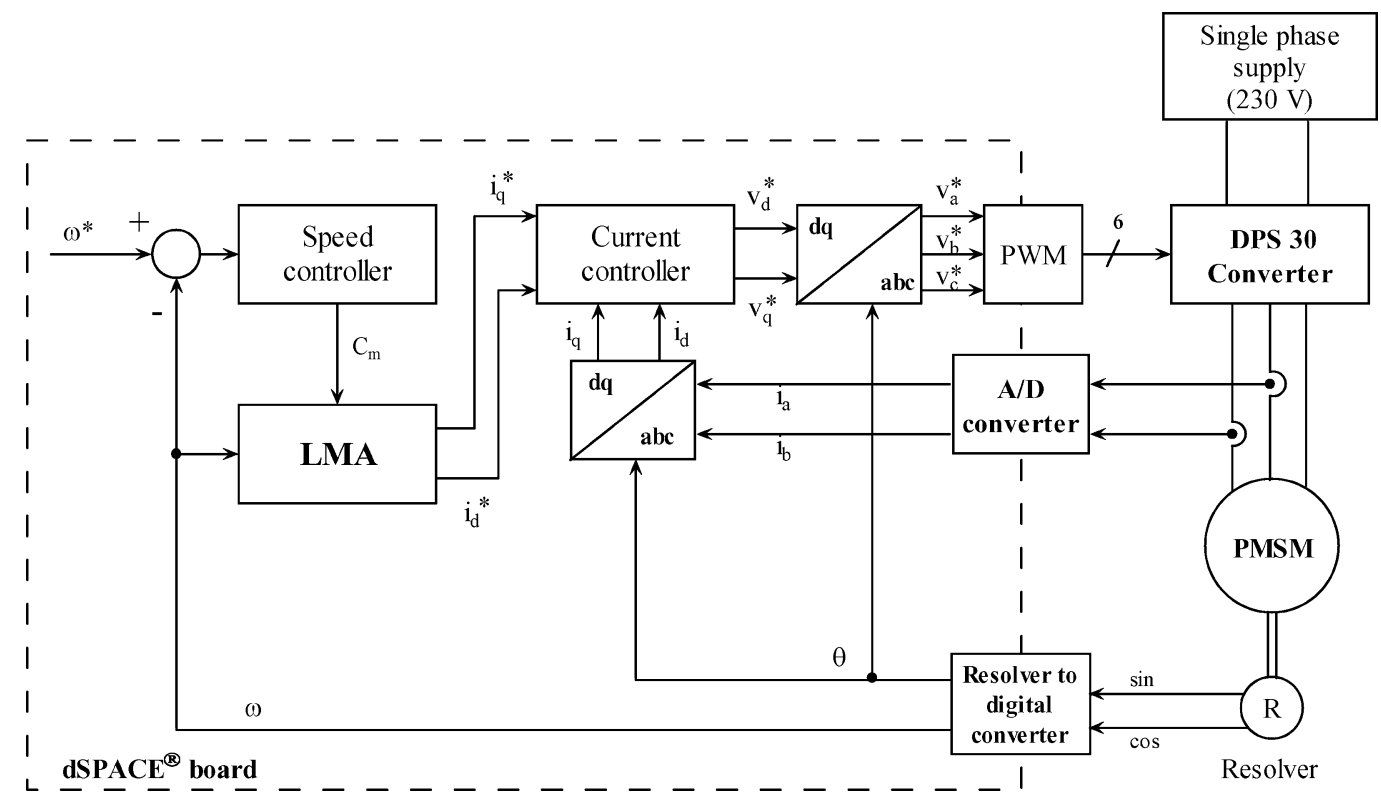

Fig. 5. Simplified schematic of the PMSM drive.

TABLE I

NAMEPLATE AND PHASE PARAMETERS OF THE PMSM

\begin{tabular}{lc}
\hline \hline Rated speed [rpm] & 4000 \\
Rated current $(\mathrm{rms})[\mathrm{A}]$ & 3.6 \\
Rated torque [Nm] & 1.8 \\
Number of poles & 6 \\
Stator winding resistance $\mathrm{R}[\Omega]$ & 2.21 \\
Core loss equivalent resistance $\mathrm{R}_{\mathrm{c}}[\Omega]$ & 840 \\
Direct axis inductance [mH] & 9.77 \\
Quadrature axis inductance [mH] & 14.94 \\
Permanent magnet flux [Wb] & 0.0844 \\
Mechanical loss [Nm] & 0.04 \\
\hline \hline
\end{tabular}

TABLE II

ELECTRICAL QUANTITIES OF THE POWER CONVERTER

\begin{tabular}{lc}
\hline \hline Input voltage (single phase) [V] & 230 \\
DC link voltage [V] & 310 \\
Output power peak [kW] & 6.5 \\
Phase current peak (crest) [A] & 30 \\
Phase current (rms) [A] & 21 \\
Switching frequency [kHz] & 20 \\
Electrical power in the load (brake) [kW] & 3.2 \\
\hline
\end{tabular}

ness of the LMA implementation on the PMSM drive control. The main characteristics of the PMSM and the power converter are listed, respectively, in Tables I and II. A selection of the experimental tests is reported here seeking to analyze and discuss the most significant results.

In particular, the estimated power losses (copper, iron, and overall controllable losses) and the measured ones relative to the PMSM drive are reported in Figs. 6 and 7 in the case of an angular speed of $3000 \mathrm{r} / \mathrm{min}$, respectively, at no-load and fullload conditions. The estimated power losses were calculated by applying (5)-(7) and (11). The measured power losses have been obtained as the difference between the PMSM input power and the output one on the brake. In these conditions the controllable losses present an experimental minimum at direct-axis currents of about $i_{d}=0.25 \mathrm{~A}$ (no-load condition) and $i_{d}=2.5 \mathrm{~A}$

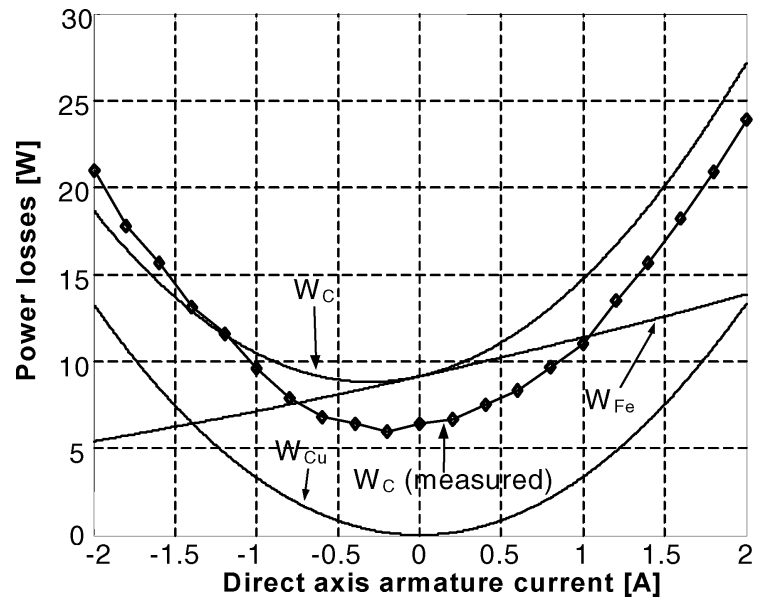

Fig. 6. Power losses of the test motor at $3000 \mathrm{r} / \mathrm{min}$ and no-load condition as a function of the direct current component. The estimated values are separated into copper and iron losses, and the measured ones are as a whole.

(full-load condition). Figs. 6 and 7 also show that the overall losses always admit a minimum, and it is, hence, possible to find a value of the direct-axis armature current that minimizes the power consumption, obtaining the condition of maximum efficiency.

Aiming to compare this power LMA with a traditional $i_{d}=0$ control, two different series of tests were carried out by using these two procedures. As far as the tests were concerned to mainly explore the gain achievable in terms of energy savings, the efficiency variation as a function of the mechanical speed in the case of the LMA (continuous curve) and of the $i_{d}=0$ control (dotted curve) is shown in Fig. 8 at the rated load torque of $1.8 \mathrm{~N} \cdot \mathrm{m}$. The efficiency of the brushless motor may increase up to $2.7 \%$, and the maximum applies especially in the high-speed range where the iron losses become more intense as compared with those in the copper. Fig. 9 shows the percentage efficiency improvement of the LMA case study (using as reference the 


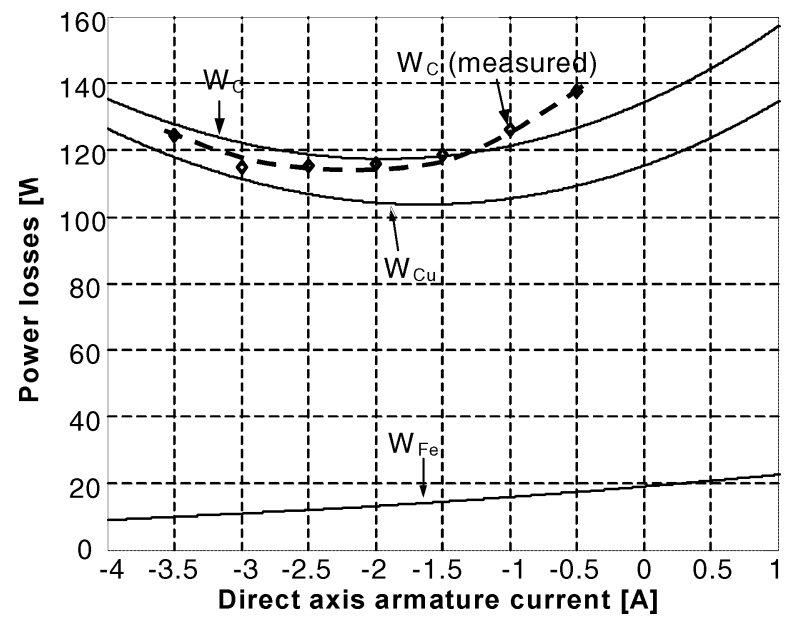

Fig. 7. Power losses of the test motor at $3000 \mathrm{r} / \mathrm{min}$ and full-load condition as a function of the direct current component. The estimated values are separated into copper and iron losses, and the measured ones are as a whole.

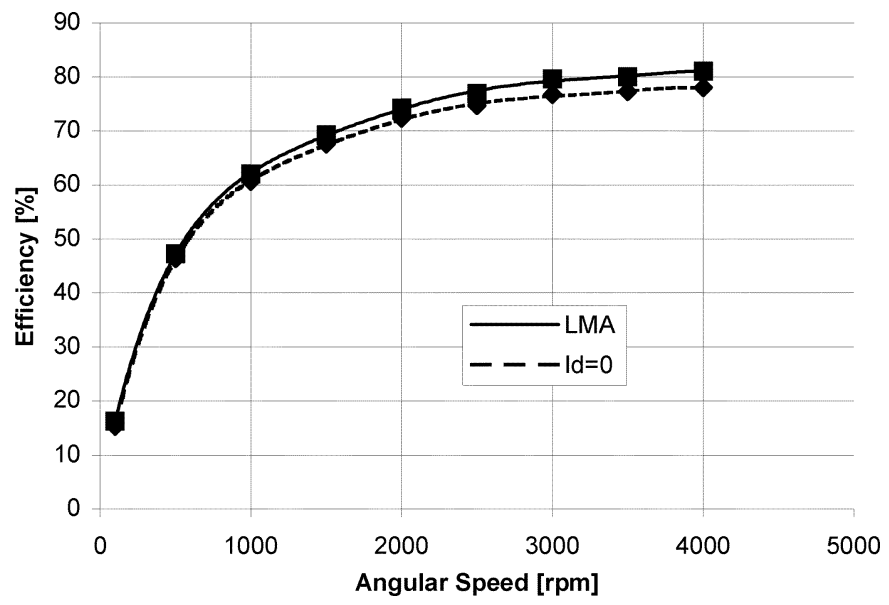

Fig. 8. Comparison of the motor efficiencies at rated load $(1.8 \mathrm{~N} \cdot \mathrm{m})$ versus the angular speed ( $\mathrm{r} / \mathrm{min}$ ) in the case of LMA (continuous curve) and of $i_{d}=0$ (dotted curve) controls.

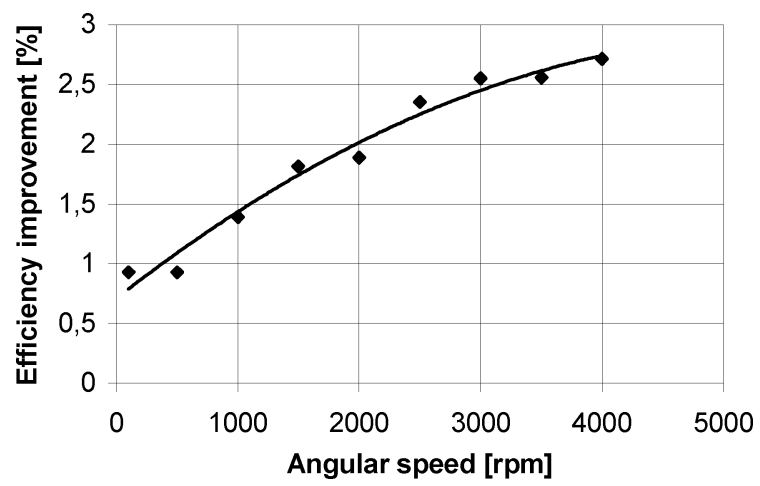

Fig. 9. Achievable efficiency improvement due to LMA (referred to the traditional control approach) versus the angular speed at rated load condition $(1.8 \mathrm{~N} \cdot \mathrm{m})$.

$i_{d}=0$ control) as a function of the angular speed, at a rated load torque of $1.8 \mathrm{~N} \cdot \mathrm{m}$.

Fig. 10 shows the efficiency variations as a function of the mechanical load torque in the case of the LMA (continuous curve) and of the $i_{d}=0$ control (dotted curve) at the rated speed of $4000 \mathrm{r} / \mathrm{min}$. By inspection of Fig. 10 it is possible to realize that

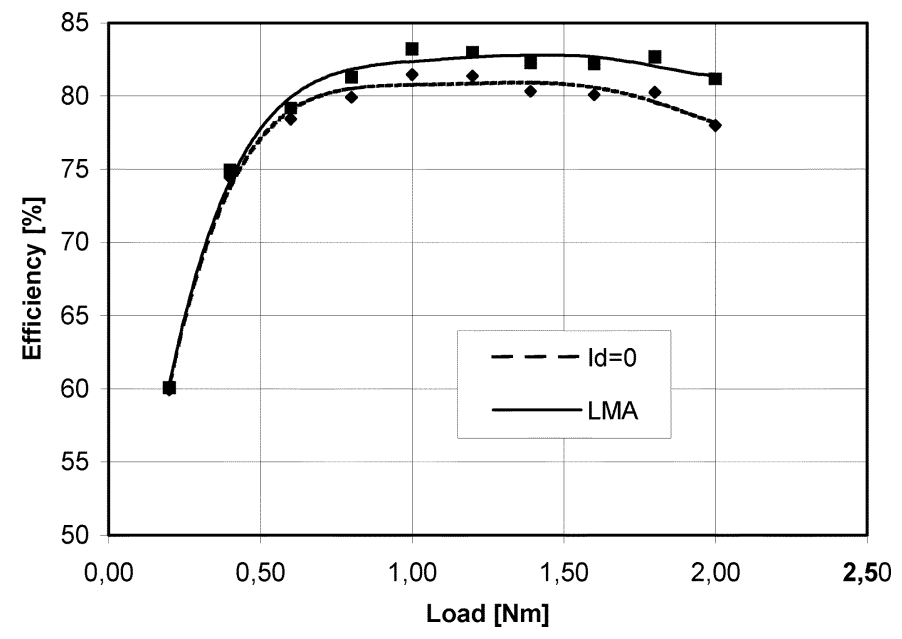

Fig. 10. Comparison of the motor efficiencies at rated speed $(4000 \mathrm{r} / \mathrm{min})$ versus the load torque in the case of LMA (continuous curve) and of $i_{d}=0$ (dotted curve) controls.

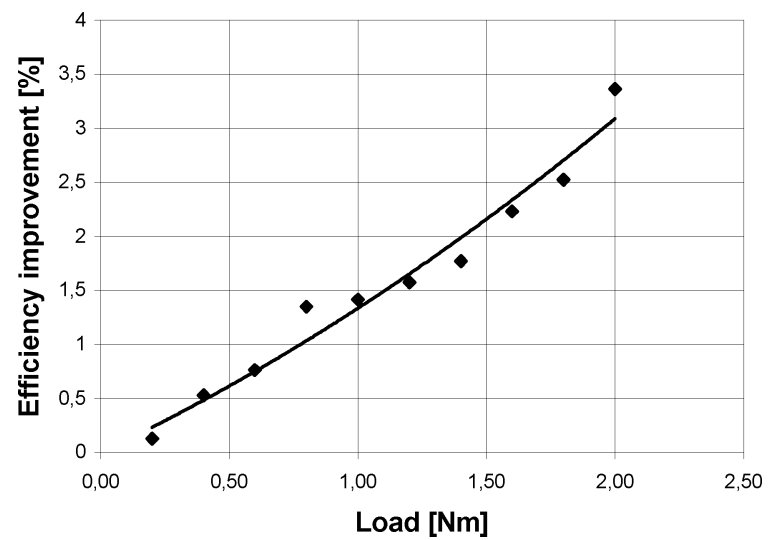

Fig. 11. Achievable efficiency improvement due to LMA (referred to the traditional control approach) versus the load torque at rated speed (4000 r/min).

the effectiveness of the LMA grows with increasing load. Fig. 11 shows the percentage of efficiency improvement of the LMA with respect to the conventional control $\left(i_{d}=0\right)$ as a function of the load torque at the rated speed of $4000 \mathrm{r} / \mathrm{min}$. A significant efficiency improvement is reached at high load and at high speed, as expected. In fact, at a torque load of $2 \mathrm{~N} \cdot \mathrm{m}$ (overload condition) the efficiency increase is about $3.5 \%$. These results prove the good performance of the LMA for a speed range up to base speed. Future work will deal with the application of the LMA for the field-weakening region, also. Obviously, since in practice small motors are designed to have lower efficiency than large motors, the interested reader should easily realize that the previous figure of efficiency enhancement is no longer to be expected for large machines. Future work of the authors will include the investigation of this issue. On the other hand, small motors are widely used and any improvement of their efficiency without increase of the drive cost is worth being obtained.

A test of the dynamic performance of the drive has been performed in order to verify differences between the proposed control and the traditional one. Fig. 12 reports the angular speeds versus time during a no-load speed reversal from -3000 to $+3000 \mathrm{r} / \mathrm{min}$ of the PMSM electrical drive for both the $i_{d}=0$ control and the LMA one. As can be observed from inspection of 


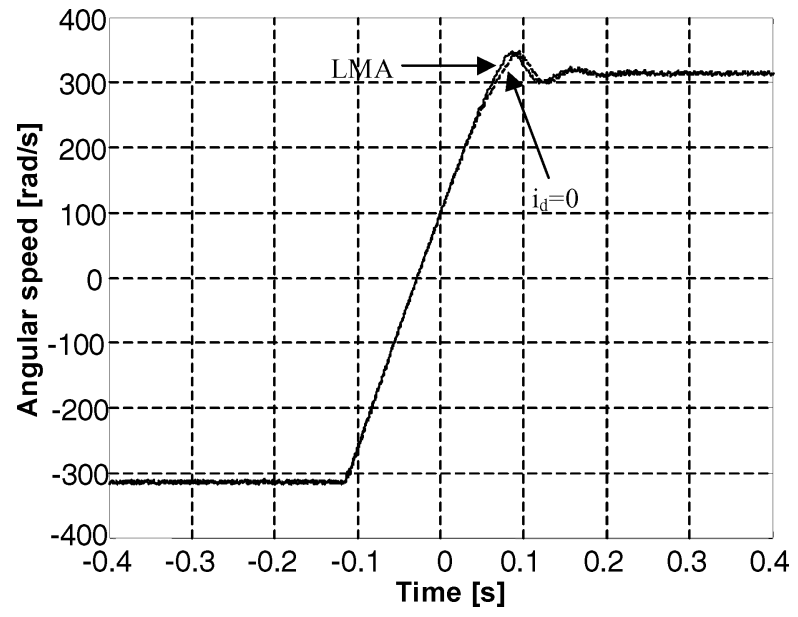

Fig. 12. Performance comparison of the dynamic performance, which is obtained by two different control strategies, of the PMSM motor drive during a speed reversal from -3000 to $+3000 \mathrm{r} / \mathrm{min}(-314$ to $314 \mathrm{rad} / \mathrm{s})$. The traces are in practice quite overlapped.

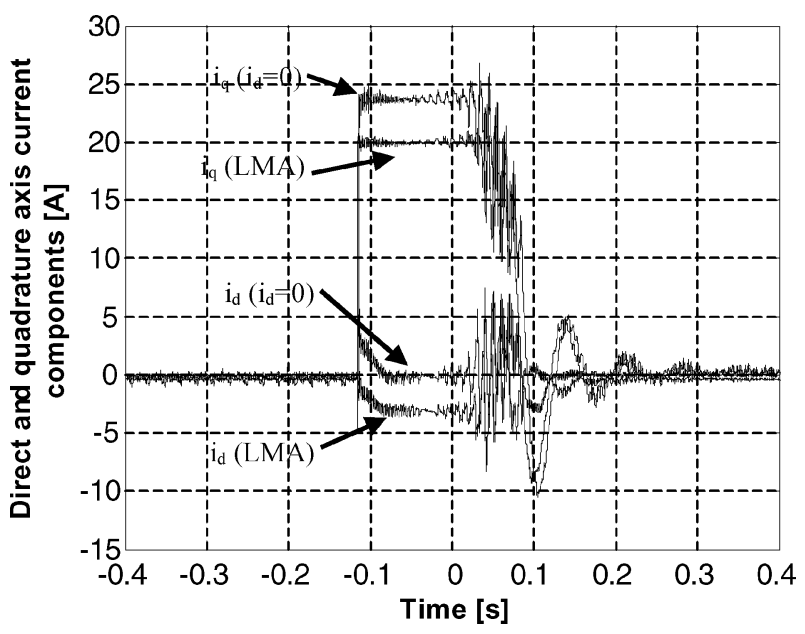

Fig. 13. Direct and quadrature motor current components during the speed reversal from -3000 to $+3000 \mathrm{r} / \mathrm{min}$ according to the test conditions of Fig. 12.

the figure, the dynamic response of the speed between the traditional control algorithm and the loss minimization one does not show appreciable differences. Finally, Fig. 13 shows the direct- and quadrature-axes currents in the same test condition of Fig. 12. It can be seen that the dynamics of the currents are quite similar, while their instantaneous values are different.

It is worth noting that at high speed the effect of the flux weakening impressed by the LMA control strategy significantly works in reducing the iron losses. Moreover, the increase of the $i_{d}$ component of the stator current (toward a negative value) changes the sign of the reluctance torque component (7), from a negative to a positive value in the case of a machine with $L_{m q}>L_{m d}$ ) and, consequently, at full-load conditions, even if the air-gap direct-axis flux and the $i_{q}$ component of the stator current are decreased, the whole electromagnetic torque is maintained constant.

\section{CONCLUSION}

In this paper a "loss-model control" strategy has been analyzed and implemented in a DSP-controlled motor drive. In particular, it has been verified by experimental tests that the control of the direct-axis stator current can minimize the controllable electrical losses occurring in a PM brushless motor drive. Such a control strategy, accounting for both the instantaneous speed value and the load torque condition, uses the combined effects of the field weakening and the exploitation of the reluctance torque looking for a reduction of the power losses, and an increase of the drive efficiency. The LMA is suitable for different brushless motor types, and it is very flexible and simple to implement because it only requires the knowledge of some common motor quantities (like the stator resistance, the iron losses, direct and quadrature inductances, etc.). The main results of the experimental tests carried out demonstrated how, in comparison to more traditional control methods, the LMA increments the efficiency of a PMSM electrical drive without any reduction of the dynamic performance. The figure of the efficiency improvement (up to $3.5 \%$ in a small motor) is valuable since we are comparing very efficient traditional algorithms with the new one, and any further improvement is difficult to achieve.

\section{ACKNOWLEDGMENT}

The authors wish to acknowledge the anonymous reviewers whose precise suggestions, qualified comments, and corrections contributed to the quality of this work.

\section{REFERENCES}

[1] S. Morimoto, Y. Tong, Y. Takeda, and T. Hirasa, "Loss minimization control of permanent magnet synchronous motor drives," IEEE Trans. Ind. Electron., vol. 41, no. 5, pp. 511-517, Oct. 1994.

[2] S. Vaez and M. A. Rahaman, "Adaptive loss minimization control of inverter-fed IMP motor drives," in Proc. IEEE PESC'97, vol. 2, Jun. 22-27, 1997, pp. 861-868.

[3] T. M. Jahns, G. B. Kliman, and T. W. Neumann, "Interior permanentmagnet synchronous motors for adjustable-speed drives," IEEE Trans. Ind. Appl., vol. IA-22, no. 4, pp. 738-747, Jul./Aug. 1986.

[4] C. Cavallaro, A. O. Di Tommaso, R. Miceli, A. Raciti, G. R. Galluzzo, and M. Trapanese, "Efficiency improvement of inverter-fed permanent magnet synchronous motors," in Proc. 3rd Int. Conf. Energy Efficiency in Motor Driven Systems, EEMODS'02, Treviso, Italy, Sep. 18-20, 2002, pp. 490-497.

[5] R. S. Colby and D. W. Novotny, "Efficient operation on surface-mounted PM synchronous motors," IEEE Trans. Ind. Appl., vol. IA-23, no. 6, pp. 1048-1054, Nov./Dec. 1987.

[6] _ , "An efficiency-optimizing permanent magnet synchronous motor drive," IEEE Trans. Ind. Appl., vol. 24, no. 3, pp. 462-469, May/Jun. 1988.

[7] S. Morimoto, Y. Takeda, and T. Hirasa, "Current phase control methods for permanent magnet synchronous motors," IEEE Trans. Ind. Electron., vol. 5, no. 2, pp. 133-139, Apr. 1990.

[8] C. Mademlis, J. Xypteras, and N. Margaris, "Loss minimization in surface permanent-magnet synchronous motor drives," IEEE Trans. Ind. Electron., vol. 47, no. 1, pp. 115-122, Feb. 2000.

[9] F. Fernandèz-Bernal, A. G. Cerrada, and R. Faure, "Model-based loss minimization for DC and AC vector controlled motors including core saturation," IEEE Trans. Ind. Appl., vol. 36, no. 3, pp. 755-763, May/Jun. 2000.

[10] F. Abrahamsen, F. Blaabjerg, J. K. Pedersen, and P. B. Thøgersen, "Efficiency-optimized control of medium-size induction motor drives," IEEE Trans. Ind. Appl., vol. 37, no. 6, pp. 1761-1767, Nov./Dec. 2001.

[11] B. S. Gottfried, Programming with Pascal. New York: McGraw-Hill, 1985. 


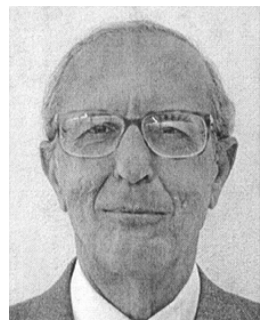

Calogero Cavallaro was born in Catania, Italy, in 1945. He received the Electrotechnical Engineering degree from the Politecnico di Torino, Turin, Italy, in 1969.

From 1971 to 1982, he was an Assistant Professor of Electrotechnical Engineering at the University of Catania, Catania, Italy, where, from 1982 to 2002, he was an Associate Professor of Electrical Machines. Since March 2002, he has been a Full Professor of Electrical Engineering in the Department of Electrical, Electronic, and Systems Engineering. He has specialized his scientific activity in the field of electrical machines, electronic devices, energy conversion systems, electrical drives, and power electronics. In recent years his research activities have been devoted to the analysis and modeling of electrical machines, new or innovative power devices, and applications of emerging technologies in the field of electrical drives. This activity has been substantiated by several technical and scientific papers which have been presented at conferences or published in international journals. $\mathrm{He}$ is the author of more than 70 technical papers.

Prof. Cavallaro is a Member of the Italian Association of Electrical and Electronics Engineers (FAEIT).

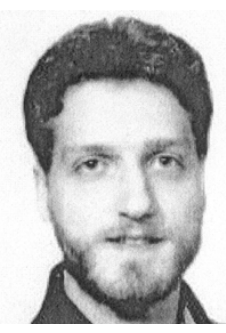

Antonino Oscar Di Tommaso received the Electrical Engineering and $\mathrm{Ph} . \mathrm{D}$. degrees from the University of Palermo, Palermo, Italy, in 1999 and 2004, respectively.

$\mathrm{He}$ is currently a Postdoctoral Fellow in the Department of Electrical Engineering, University of Palermo, where his work involves electrical machines and drives.

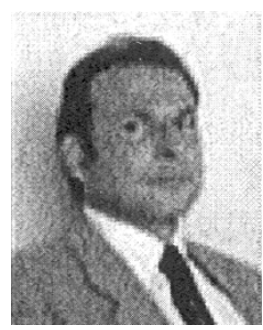

Rosario Miceli (M'02) received the Electrical Engineering and Ph.D. degrees from the University of Palermo, Palermo, Italy.

$\mathrm{He}$ is currently an Associate Professor with the Faculty of Engineering, University of Palermo. His main research interests include mathematical models of electrical machines, drive systems control, and diagnostics.

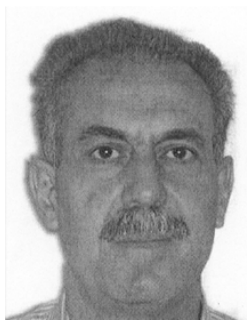

Angelo Raciti (M'93-SM'98) received the "Laurea" degree (summa cum laude) in electrical engineering from the University of Catania, Catania, Italy, in 1975.

In 1976, he joined Intar Spa, Genoa, Italy, where he was an Engineer and Manager, involved in the development of advanced equipment for industrial and ship applications, with special responsibility for power electronics design. In 1981, he joined the Department of Electrical, Electronics, and Systems Engineering, University of Catania, where he is a Full Professor, teaching power electronics. His teaching and research interests lie in the areas of electrical machines, semiconductor power devices, power electronics, and electrical drives.

Dr. Raciti is a Senior Member of the Italian Association of Electrical and Electronics Engineers (FAEIT). He serves as a Member of the Power Devices and Passive Components Committee of the IEEE Industry Applications Society.

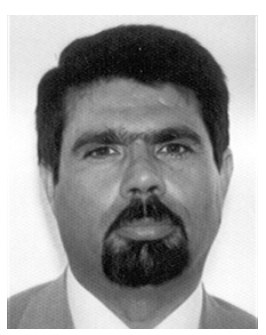

Giuseppe Ricco Galluzzo received the Electrical Engineering degree from the University of Palermo, Palermo, Italy.

During 1992-2001, he was an Associate Professor of Electrical Drives at the University of Palermo, where, since September 2001, he has been a Full Professor. His research involves the fields of mathematical models of electrical machines and drive systems control and diagnostics.

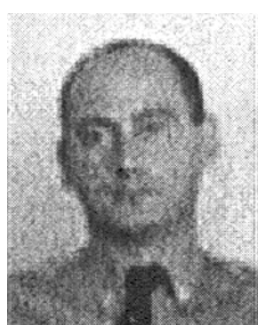

Elettrotecnica Italiana.
Marco Trapanese (M'99) received the "Laurea" degree in physics, the "Laurea" degree in electrical engineering, and the Ph.D. degree in electrical engineering from the University of Palermo, Palermo, Italy.

He is currently a Researcher and Teaching Assistant with the Faculty of Engineering, University of Palermo. His research involves the fields of mathematical models of electrical machines, drive systems control, and diagnostics.

Dr. Trapanese is a Member of the Associazione 